\title{
Resgate vegetativo e propagação de cedro-australiano por estaquia
}

\author{
Mariane de Oliveira Pereira ${ }^{(1)}$, Ivar Wendling ${ }^{(2)}$, Antonio Carlos Nogueira(1), \\ Antonio Nascim Kalil Filho ${ }^{(2)}$ e Marcio Carlos Navroski(3)
}

\begin{abstract}
(1)Universidade Federal do Paraná, Setor de Ciências Agrárias, Avenida Prefeito Lothário Meissner, no 900, CEP 80210-170 Curitiba, PR, Brasil. E-mail: maripereira.florestal@gmail.com, nogueira@ufpr.br (2)Embrapa Florestas, Estrada da Ribeira, Km 111, Caixa Postal 319, CEP 83411-000 Colombo, PR, Brasil. E-mail: ivar.wendling@embrapa.br, antonio.kali@@embrapa.br (3)Universidade do Estado de Santa Catarina, Centro de Ciências Agroveterinárias, Avenida Luiz de Camões, no 2.090, CEP 88520-000 Lages, SC, Brasil. E-mail: marcio.navroski@udesc.br
\end{abstract}

Resumo - O objetivo deste trabalho foi avaliar métodos de resgate vegetativo para a produção de estacas (corte raso, anelamento total e semianelamento) de árvores adultas de cedro-australiano (Toona ciliata var. australis). Avaliou-se o número de brotos produzidos aos 60,120 e 180 dias, bem como a correlação entre o diâmetro médio do tronco à altura do peito (DAP) e o número de brotos. Com as brotações resultantes de cada método, produziram-se estacas que foram submetidas à retirada e ao corte de folíolos, e então receberam a aplicação de ácido indolbutírico (AIB) (0 e $\left.6.000 \mathrm{mg} \mathrm{L}^{-1}\right)$. Avaliou-se a influência dos fatores método de resgate, tempo de coleta, número de folíolos das estacas e planta matriz, em presença e ausência de AIB, na sobrevivência e no enraizamento das estacas. Não houve correlação entre o DAP das árvores e o número de brotações. $\mathrm{O}$ corte raso aos 120 dias proporcionou a maior produção de brotos (15,31). Estacas obtidas do semianelamento apresentaram maior sobrevivência $(57,8 \%)$ e enraizamento $(55,5 \%)$. Estacas com dois pares de folíolos inteiros e tratadas com $6.000 \mathrm{mg} \mathrm{L}^{-1}$ de AIB apresentaram maior sobrevivência (65,5\%) e enraizamento (56,7\%). Houve grande variação na sobrevivência e no enraizamento entre plantas matrizes. O resgate vegetativo e a estaquia apresentam potencial para multiplicação clonal de árvores adultas de cedro-australiano.

Termos para indexação: Toona ciliata, enraizamento, propagação assexuada, propagação vegetativa, silvicultura clonal.

\section{Vegetative rescue and propagation of Australian red cedar by cuttings}

\begin{abstract}
The objective of this work was to evaluate vegetative rescue methods for the production of cuttings (clearcutting, full annealing, and half-annealing) of red cedar (Toona ciliata var. australis) mature trees. The number of produced shoots was evaluated at 60,120 and 180 days, as well as the correlation between stem mean diameter at breast height (DBH) and the number of sprouts. From the resulting sprouts of each method, cuttings were produced and subjected to cutting and removal of leaflets, and then received the application of indolbutyric acid (IBA) $\left(0\right.$ and $\left.6,000 \mathrm{mg} \mathrm{L}^{-1}\right)$. Evaluations were made for the influence of the following factors on plant survival and rooting: rescue method, collection time, number of leaflets of cuttings, and matrix tree, in the presence and absence of IBA. There was no correlation between the DBH of trees and the number of produced shoots. Clearcutting at 120 days provided the highest increase of shoots (15.31). Cuttings obtained from half-annealing had higher survival (57.8\%) and rooting (55.5\%) rates. Cuttings with two pairs of preserved leaflets and treated with $6,000 \mathrm{mg} \mathrm{L}^{-1}$ IBA showed higher rates of survival $(65.5 \%)$ and rooting $(56.7 \%)$. There was wide variation in survival and rooting capacity among matrix trees. The vegetative rescue and propagation by cuttings have potential for clonal multiplication of Australian red cedar mature trees.
\end{abstract}

Index terms: Toona ciliata, rooting, assexual propagation, vegetative propagation, clonal forestry.

\section{Introdução}

A demanda pelo cultivo de novas espécies florestais como cedro-australiano, mogno-africano, nim-indiano e teca, entre outras, tem aumentado, e a madeira de tais espécies vem sendo cada vez mais valorizada economicamente. Entre as espécies alternativas potenciais para a produção de madeira nobre, Toona ciliata var. australis (F. Muell.) Bahadur, da família Meliaceae, conhecida popularmente como cedro-australiano, vem-se destacando em países como Brasil, Argentina, Havaí, Porto Rico, Honduras e outros. Esta espécie é originária da Austrália e de parte da Ásia (Bygrave \& Bygrave, 2005). 
Diversos estudos têm sido feitos para o melhoramento do cedro-australiano, nos mais variados aspectos (Souza et al., 2009; Santos, 2011; Ferreira et al., 2012; Lamônica, 2013). O método de propagação mais utilizado para a espécie é via seminal, mas a oferta sazonal das sementes e sua curta viabilidade ao longo do tempo, mesmo sendo ortodoxas, representam problemas para a oferta contínua de mudas, para a implantação de povoamentos. A maioria dos plantios tem sido realizada com material de origem seminal e sem nenhum controle genético sobre as sementes coletadas para tal finalidade (Ferreira et al., 2012). Assim, há necessidade de seleção de genótipos mais adaptados às diversas condições ambientais e mais produtivos, o que possibilita maior retorno econômico aos investidores.

Para a maximização de características de interesse - como alta produtividade, tolerância a pragas e doenças, melhoria de características da madeira -, é indispensável que sejam selecionados materiais genéticos superiores. Porém, em razão da grande variabilidade dos povoamentos e da consequente manifestação de características genéticas indesejáveis (Souza et al., 2009), é necessário o desenvolvimento de pesquisas para seleção e propagação vegetativa da espécie.

As matrizes selecionadas e multiplicadas assexuadamente constituem os clones, e o processo de multiplicação se inicia com o resgate do material superior. Para tanto, o primeiro passo após a seleção da matriz é a promoção de seu rejuvenescimento ou revigoramento, por meio da indução de brotações juvenis, que são fisiologicamente mais aptas ao enraizamento e têm maior vigor de crescimento (Wendling et al., 2014). Segundo esses autores, a forma mais eficiente de rejuvenescimento e revigoramento de árvores adultas é a indução de brotações basais, por meio do corte raso da planta-matriz. No entanto, com o uso deste método de resgate vegetativo, tem-se a desvantagem da perda da copa ou mesmo perda total do genótipo selecionado (Bitencourt et al., 2009; Wendling et al., 2013), o que justifica o desenvolvimento de métodos de resgate alternativos.

Poucos estudos referentes à propagação vegetativa do cedro-australiano foram desenvolvidos, em que se destacam Souza et al. (2009) e Silva et al. (2012), ambos com materiais juvenis de origem seminal, e Lamônica (2013), com material oriundo de brotações do corte raso de árvores com 6 anos de idade. No entanto, até o presente, não se encontraram registros na literatura do uso de materiais retirados de árvores com ciclo completo de corte (acima de 12 anos).

O objetivo deste trabalho foi avaliar métodos de resgate vegetativo, para a produção de estacas (corte raso, anelamento e semianelamento) de árvores adultas de cedro-australiano (Toona ciliata var. australis).

\section{Material e Métodos}

O material vegetal utilizado foi coletado no Município de Adrianópolis, PR, em um plantio experimental de Toona ciliata var. australis da Embrapa Florestas, implantado em fevereiro de 1999, na empresa Berneck $\left(24^{\circ} 42^{\prime} 45^{\prime \prime} \mathrm{S}, 48^{\circ} 44^{\prime} 58^{\prime \prime} \mathrm{W}\right)$. O referido plantio foi realizado com mudas obtidas de sementes provenientes da empresa Fibria (Aracruz, ES), e a origem das sementes na Austrália é desconhecida. O solo da região é classificado como Neossolo Regolítico eutrófico, com relevo fortemente ondulado e declividade entre 20 e $45 \%$ (Santos et al., 2006).

No experimento de resgate vegetativo, todas as árvores do plantio foram utilizadas, o que totalizou 16 plantas matrizes, para cada tratamento, e 48 árvores no total. Todas as árvores apresentaram bom desenvolvimento de copa, ausência de sintomas de deficiência nutricional ou hídrica e de ocorrência de pragas e doenças. As árvores selecionadas apresentaram

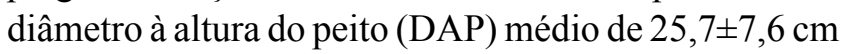
e altura média de $33,5 \pm 6,1 \mathrm{~m}$. Os dados do DAP foram utilizados para verificar a existência de correlação do número de brotações com o diâmetro das árvores.

A influência do método de resgate vegetativo sobre o número de brotações foi avaliada em um delineamento experimental inteiramente casualizado, com 16 repetições de uma planta (48 árvores no total), em arranjo fatorial $3 \times 3$ - três métodos de resgate (anelamento, semianelamento e corte raso das árvores) e três tempos de coletas $(60,120$ e 180 dias após tratamento de resgate). Os tratamentos consistiram dos métodos de resgate. $\mathrm{O}$ anelamento e o corte raso foram realizados conforme Almeida et al. (2007) e Santin et al. (2008).

Para o anelamento e o semianelamento, foram traçadas duas linhas transversais no tronco de cada árvore, com o auxílio de um facão, tendo-se cortado somente a espessura da casca. Posteriormente, com 
o auxílio de um formão de carpinteiro, foi removido um anel de casca de $2 \mathrm{~cm}$ de largura entre as linhas formadas, tendo-se tomado o cuidado de não danificar o lenho. Esses procedimentos foram realizados a $30 \mathrm{~cm}$ do solo, em média. No anelamento, removeu-se 100\% da circunferência do tronco e, no semianelamento, $50 \%$. $\mathrm{O}$ corte raso das árvores foi feito com o auxílio de uma motosserra, à altura similar aos outros tratamentos.

Realizaram-se três coletas de brotações aos 60 (setembro de 2012), 120 (dezembro de 2012) e 180 (março de 2013) dias após a execução dos procedimentos de anelamento, semianelamento e corte raso e, a cada coleta, registrou-se o número de brotações nas árvores em que foram realizados esses tratamentos. As brotações foram cortadas quando apresentavam aproximadamente $25 \mathrm{~cm}$ de comprimento, colocadas em caixa de isopor, com gelo ao fundo, cobertas por folhas de jornal umedecido com água e levadas para o Laboratório de Propagação de Espécies Florestais, da Embrapa Florestas, em Colombo, PR. Foram preparadas estacas com comprimento médio de $10 \mathrm{~cm}$, corte em bisel na base e reto no ápice, tendo-se mantido ou retirado os folíolos, conforme o experimento. Como controle fitossanitário, as estacas foram mergulhadas durante $5 \mathrm{~min}$ em solução de hipoclorito de sódio a $2,5 \%$, seguida de imersão total em água corrente, durante $5 \mathrm{~min}$, e de imersão total em fungicida com princípio ativo benomyl a $5 \%$, por $5 \mathrm{~min}$.

Para a avaliação da influência dos três métodos de resgate e do ácido indolbutírico (AIB) no enraizamento das estacas, utilizou-se somente o material da segunda coleta (dezembro de 2012, durante o verão), em razão do baixo número de brotações dos tratamentos de anelamento e semianelamento na primeira e terceira coletas. Utilizou-se o delineamento experimental inteiramente casualizado, em arranjo fatorial $(3 \times 2)$, com três métodos de resgate e presença $\left(6.000 \mathrm{mg} \mathrm{L}^{-1}\right)$ ou ausência $\left(0 \mathrm{mg} \mathrm{L}^{-1}\right)$ de AIB, com cinco repetições de 10 estacas. A concentração de $6.000 \mathrm{mg} \mathrm{L}^{-1}$ de AIB foi utilizada conforme recomendado por Xavier et al. (2013), em material de resgate vegetativo de árvores adultas de Ilex paraguariensis e em diversas espécies de Eucalyptus spp.

Estacas do tratamento com AIB foram imersas em solução hidroalcoólica $(50 \% \mathrm{v} / \mathrm{v})$, somente pela parte basal, durante $10 \mathrm{~s}$, antes de serem imersas em AIB a $6.000 \mathrm{mg} \mathrm{L}^{-1}$. As estacas do tratamento sem AIB foram imersas somente em solução hidroalcoólica $(50 \% \mathrm{v} / \mathrm{v})$.
As estacas foram colocadas para enraizar em tubetes médios $\left(110 \mathrm{~cm}^{3}\right)$ que continham uma mistura de substrato comercial Tecnomax e vermiculita média $(1: 1 \mathrm{v} / \mathrm{v})$.

Os tubetes com as estacas foram acondicionados em casa de vegetação, por 30 dias, a 20 e $30^{\circ} \mathrm{C}$, com umidade relativa (UR) do ar superior a $80 \%$, e irrigados por nebulização. A temperatura e a UR do ar foram controladas automaticamente por termostato e umidostato, respectivamente.

Estacas produzidas a partir das brotações emitidas aos 60 dias, após a realização do tratamento de corte raso, foram utilizadas para avaliação do enraizamento, em razão do número de folíolos remanescentes nas estacas e do uso de AIB. Utilizaram-se estacas somente do corte raso, em razão da baixa produção de estacas dos tratamentos de anelamento e semianelamento, para evitar eventuais diferenças no enraizamento decorrentes do método de resgate. $\mathrm{O}$ experimento foi realizado em delineamento inteiramente casualizado, em arranjo fatorial $3 \times 2$, cujos fatores foram: a quantidade de folíolos por estaca - sem folíolos, 2 pares de folíolos cortados ao meio e 2 pares de folíolos inteiros; e a presença $\left(6.000 \mathrm{mg} \mathrm{L}^{-1}\right)$ ou ausência $\left(0 \mathrm{mg} \mathrm{L}^{-1}\right)$ de AIB. Foram utilizadas cinco repetições de 20 estacas. A aplicação do AIB, o estaqueamento e acondicionamento em casa de vegetação seguiram o procedimento descrito no experimento anterior.

$\mathrm{Na}$ avaliação da influência da planta matriz sobre o enraizamento, utilizaram-se estacas produzidas a partir de brotações emitidas aos 120 dias, dos tratamentos de corte raso e anelamento. A baixa quantidade de brotações, na primeira e terceira coletas, principalmente no tratamento de semianelamento, impossibilitou a repetição do experimento em todas as coletas realizadas.

Para esse experimento, foram selecionadas para tratamento sete árvores matrizes (M02 a M16) com superioridade em DAP e altura (M02, 36,6 cm e $35,6 \mathrm{~m} ; \mathrm{M} 04,32,2 \mathrm{~cm}$ e $33,4 \mathrm{~m} ; \mathrm{M} 05,34,4 \mathrm{~cm}$ e $35,3 \mathrm{~m} ; \mathrm{M} 08,33,7 \mathrm{~cm}$ e $34,2 \mathrm{~m} ; \mathrm{M} 10,32,5 \mathrm{~cm}$ e 35,1 m; M11,32,9 cm e 34,6 m; M16, 38,8 cm e 37, 2 m), com número de brotos suficientes para a realização do estudo. $\mathrm{O}$ experimento foi realizado em delineamento inteiramente casualizado, em arranjo fatorial $7 \times 2$, com sete plantas matrizes e presença $\left(6.000 \mathrm{mg} \mathrm{L}^{-1}\right)$ ou ausência $\left(0 \mathrm{mg} \mathrm{L}^{-1}\right)$ de AIB. Utilizaram-se cinco repetições de 15 estacas. A aplicação de AIB e de 
estaqueamento e acondicionamento em casa de vegetação seguiram o procedimento descrito nos experimentos anteriores.

Nas avaliações realizadas com as estacas produzidas, as variáveis foram: percentagem de sobrevivência das estacas (S), percentagem de enraizamento (E) e número de raízes por estaca (NR). No experimento de enraizamento em função do método de resgate, avaliou-se também o diâmetro medido na base das estacas $(\mathrm{cm})$. Consideraram-se sobreviventes as estacas que apresentavam lenho vivo, folhas velhas ou brotações jovens, enraizadas ou não. A percentagem de estacas enraizadas foi considerada sobre o total, não somente sobre as estacas sobreviventes. Considerou-se como enraizada a estaca com indução de primórdios radiculares de, no mínimo, $1 \mathrm{~mm}$ de comprimento.

Após a verificação da normalidade dos dados, por meio do teste de Kolmogorov-Smirnov, e da homogeneidade pelo teste de Bartlett, realizou-se a análise de variância. Quando necessário, os dados foram transformados pela função $(\mathrm{x}+0,5)^{0,5}$, e as médias foram comparadas pelo teste de Scott-Knott, a $5 \%$ de probabilidade.

\section{Resultados e Discussão}

Em nenhum dos tratamentos de resgate, se observou morte de árvores, o que mostra que a espécie suporta a retirada de um anel parcial e total da casca, sem que se prejudique sua sobrevivência. Não houve correlação entre o DAP das árvores selecionadas e o número de brotações produzidas, independentemente do método de resgate e época de coleta. Todas as árvores em que se realizou o corte raso emitiram brotações, diferentemente daquelas do anelamento parcial e total.

Houve interação significativa entre o período de coleta e o método de resgate, quanto ao número de brotos por árvore. No semianelamento, não se observou diferença entre as três coletas realizadas; no anelamento e corte raso, observou-se maior produção de brotações na segunda coleta em dezembro (Tabela 1).

O maior número de brotos na segunda coleta pode ter sido influenciado pela presença de gemas que permaneceram dormentes, após a aplicação dos tratamentos, e não geraram brotações após a primeira coleta ou, ainda, pode ter sido influenciado por uma morfogênese originada da transformação de células do câmbio ao longo do tempo (Rast et al., 1988).
A terceira coleta, realizada em março, no início do outono, apresentou redução da produção de brotações (Tabela 1), provavelmente em razão da redução metabólica e fisiológica das plantas, durante essa estação, e da cicatrização da parte anelada e semianelada, bem como da redução do vigor após as primeiras coletas de brotações. A redução de brotações com a cicatrização também foi observada em árvores de Eucalyptus cloeziana, de 5 a 10 anos de idade, submetidas ao anelamento (Almeida et al., 2007).

Dos métodos de resgate, o corte raso foi o que resultou em maior número de brotos, nas três coletas, o que, provavelmente, é consequência do aumento da relação citocinina/auxina e do estresse originado com a quebra total da dominância apical no corte raso (Hartmann et al., 2011). O corte raso é um dos métodos de resgate mais utilizados na área florestal, em razão, principalmente, do grande número de brotações que surgem ao longo da cepa remanescente, em comparação a outras técnicas de resgate (Bitencourt et al., 2009).

Em Eucalyptus cloeziana, o resgate de brotações das cepas provenientes do corte raso das árvores mostrouse mais viável do que o método do anelamento do caule e da indução de brotações epicórmicas em galhos podados, tanto pelo maior número de brotações emitidas, quanto pela sua capacidade de enraizamento (Almeida et al., 2007). Em um estudo com matrizes adultas de Araucaria angustifolia, em que o corte raso foi utilizado como método para indução de brotações epicórmicas, foi possível observar a viabilidade desse método para o resgate de matrizes selecionadas (Wendling et al., 2009).

Apesar de, no presente trabalho, o anelamento do caule ter induzido menor número de brotações do que o corte raso, esse método pode ser utilizado nos casos em que o corte raso não é permitido, ou quando ocorre

Tabela 1. Número médio de brotos por árvore, em diferentes tempos de coleta, e método de resgate para produção de estacas de Toona ciliata var. australis ${ }^{(1)}$.

\begin{tabular}{lccc}
\hline Método de resgate & \multicolumn{3}{c}{ Tempo de coleta } \\
\cline { 2 - 4 } & 60 dias & 120 dias & 180 dias \\
\hline Semianelamento & $0,20 \mathrm{bA}$ & $1,33 \mathrm{cA}$ & $0,00 \mathrm{bA}$ \\
Anelamento & $0,76 \mathrm{bB}$ & $4,88 \mathrm{bA}$ & $0,29 \mathrm{bB}$ \\
Corte raso & $5,06 \mathrm{aB}$ & $15,31 \mathrm{aA}$ & $6,25 \mathrm{aB}$ \\
\hline
\end{tabular}

${ }^{(1)}$ Médias seguidas por letras iguais, maiúsculas nas linhas e minúsculas nas colunas, não diferem entre si, pelo teste de Scott-Knott, a 5\% de probabilidade. 
elevada mortalidade após a decepa (Santin et al., 2008). Assim, pode-se classificar a técnica de anelamento como viável, pois não ocasionou mortalidade das árvores e resultou na indução de um razoável número de brotações ( 0,3 a 4,9 por árvore). Portanto, embora não seja tão eficiente quanto o corte raso, em termos de produção de brotos, o anelamento pode ser adotado para indução de brotações basais juvenis com boa aptidão à propagação clonal de cedro-australiano. O semianelamento, entretanto, não se mostrou viável para a indução de brotações, pois somente $55 \%$ das árvores submetidas a este tratamento apresentaram brotações, além de terem ocorrido em pequeno número ( 0,0 a 1,3 por árvore).

Não houve diferença entre os métodos de resgate, na ausência de AIB, quanto à sobrevivência e ao enraizamento das estacas, embora a maior taxa de sobrevivência tenha sido observada no corte raso, na ausência de AIB (Tabela 2). Na presença de AIB $\left(6.000 \mathrm{mg} \mathrm{L}^{-1}\right)$, as estacas provenientes do semianelamento apresentaram sobrevivência e enraizamento superiores aos dos demais tratamentos, com incremento de 59\% no enraizamento, em comparação ao anelamento, e de $73 \%$ em comparação ao corte raso. Essa diferença na sobrevivência das estacas, verificada somente com o uso de AIB, pode ser atribuída à diferença de diâmetro entre as estacas obtidas em cada método. As estacas provenientes do semianelamento, que apresentaram a maior sobrevivência, tiveram menor diâmetro (média de $0,5 \mathrm{~cm}$ ) do que as do anelamento (média de $0,8 \mathrm{~cm}$ ) e do corte raso $(1,2 \mathrm{~cm})$. Nas plantas avaliadas, as estacas de maior diâmetro (anelamento e corte raso) apresentaram menor rigidez e interior com aparência esponjosa, o que pode ter colaborado para a perda

Tabela 2. Percentagem de sobrevivência, percentagem de enraizamento e número de raízes de Toona ciliata var. australis, em função do método de resgate e do uso de ácido indolbutírico (AIB) a 0 e $6.000 \mathrm{mg} \mathrm{L}^{-1(1)}$.

Método de Sobrevivência Enraizamento № de raízes

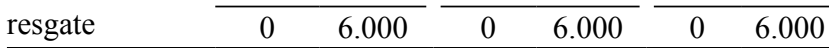

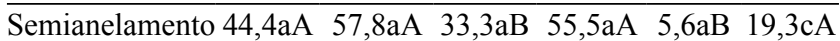
Anelamento $39,0 \mathrm{aA} \quad 38,0 \mathrm{bA} \quad 28,5 \mathrm{aA} \quad 35,0 \mathrm{bA} \quad 8,7 \mathrm{aB} \quad 28,1 \mathrm{bA}$ Corte raso $\quad 47,0 \mathrm{aA} \quad 32,0 \mathrm{bB} \quad 28,0 \mathrm{aA} \quad 32,0 \mathrm{bA} \quad 10,4 \mathrm{aB} 34,8 \mathrm{aA}$

${ }^{(1)}$ Médias seguidas por letras iguais, maiúsculas nas linhas e minúsculas nas colunas, não diferem entre si, pelo teste de Scott-Knott, a 5\% de probabilidade. de água e morte da estaca. Essas diferenças quanto à sobrevivência das estacas, de acordo com a classe de diâmetro, foram destacadas em estudo sobre Anadenanthera macrocarpa por Dias et al. (2012).

A sobrevivência das estacas provenientes do semianelamento e do anelamento não variou com o uso de AIB, diferentemente do tratamento de corte raso, que resultou em maior mortalidade com o uso da auxina (Tabela 2). As estacas do tratamento de semianelamento apresentaram maior enraizamento com o uso do AIB; essa diferença não foi observada nos demais tratamentos de resgate. Das estacas sobreviventes, a maioria apresentou emissão de raízes adventícias, principalmente em presença do AIB. A percentagem de enraizamento e o número de raízes por estaca não apresentaram diferença significativa entre os métodos de resgate na ausência de AIB; mas, em presença de AIB, o enraizamento aumentou em média $10 \%$, e o número de raízes aumentou de 3 a 4 vezes (Tabela 2).

O maior efeito da aplicação do AIB ocorreu no número de raízes nas estacas. A auxina, além de seu papel na iniciação dos primórdios radiciais, pode atuar na movimentação de nutrientes em direção ao tecido em formação e interferir no acúmulo de outros compostos necessários para um bom enraizamento (Costa et al., 2013). Em estudo com estacas originadas de decepa de Tectona grandis, Husen \& Pal (2007) mostraram que o uso AIB (4.000 $\mathrm{m} \mathrm{L}^{-1}$ ) promoveu maior enraizamento. Segundo os autores, o AIB produziu maior efeito nas árvores de maior idade do que nas mais novas, o que indica que a auxina exógena tem maior efeito com o aumento da idade. O uso de AIB em Gmelina arborea também resultou em acréscimo no enraizamento de estacas obtidas por corte raso (Singh \& Ansari, 2014).

Quanto à influência da retirada e corte dos folíolos na sobrevivência das estacas, a maior percentagem de sobrevivência foi obtida com uso de estacas com dois pares de folíolos inteiros, seguidos de estacas com dois pares de folíolos cortados ao meio e de estacas sem folíolos (Tabela 3). Assim, as estacas de cedro-australiano necessitam de, no mínimo, dois folíolos para sua sobrevivência e posterior enraizamento. Esse comportamento é semelhanteao encontrado em Eucalyptus urograndis (Souza et al., 2013) e Laurus nobilis (Fochesato et al., 2006). Em Laurus nobilis, a presença de folhas, independentemente de seu número, 
permitiu alta sobrevivência às estacas, (Fochesato et al., 2006).

As estacas sem folíolos não apresentaram enraizamento, independentemente da utilização de AIB (Tabela 3). O uso do AIB promoveu maior enraizamento com a presença de folíolos inteiros do que os tratamentos sem folíolos e aqueles com 2 pares de folíolos cortados ao meio. Isso mostra que essa interação é benéfica ao enraizamento das estacas de cedro-australiano. O número de raízes também apresentou efeito da interação número de folíolos e AIB, tendo sido superior com a utilização de estacas com dois pares de folíolos inteiros e em presença do AIB. Nas estacas com dois pares de folíolos cortados ao meio, o uso do AIB não influenciou o enraizamento e o número de raízes. Na ausência de AIB, o maior número de raízes foi obtido em estacas com os folíolos cortados ao meio.

A manutenção de folhas nas estacas é necessária para cedro-australiano, visto que o ácido indolacético (AIA), um dos mais importantes hormônios para o processo de iniciação radicial (Costa et al., 2013), é mais sintetizado em ápices e folhas novas (Luo et al., 2008). Esse aumento do enraizamento, com a presença de folhas nas estacas, pode ter sido ocasionado também pela síntese de carboidratos na fotossíntese e de outras substâncias que são importantes no processo de formação de raízes, o que estimula a atividade de troca e a diferenciação celular necessárias para o sucesso do enraizamento (Stenvall et al., 2009). Estacas de cedro-australiano podem emitir raízes sem o uso de AIB, desde que mantidos os folíolos, mas o enraizamento pode aumentar com uso de AIB. Resultados semelhantes foram encontrados com miniestacas de origem seminal de Cedrela fissilis, em que foi possível observar melhor desempenho das miniestacas com presença de folhas em comparação ao enraizamento (Xavier et al., 2003). Em Eucalyptus grandis x E. urophylla, também se observou maior enraizamento das estacas com a manutenção das folhas (Souza et al., 2013).

A influência da planta matriz e da interação com o AIB foi observada na sobrevivência das estacas, (Tabela 4). A diferença entre a matriz que apresentou menor sobrevivência (M02) e a que apresentou a maior (M16) foi superior a 20\%, o que é indicação da influência da variação genética na estaquia da espécie. A variação genotípica na sobrevivência de estacas foi

Tabela 3. Percentagem de sobrevivência e de enraizamento, e número de raízes em estacas de Toona ciliata var. australis, em função da presença de folíolos nas estacas e do uso de ácido indolbutírico (AIB) a 0 e $6.000 \mathrm{mg} \mathrm{L}^{-1(1)}$.

\begin{tabular}{|c|c|c|c|c|c|}
\hline \multirow[t]{2}{*}{ Estacas } & \multirow[t]{2}{*}{ Sobrevivência $^{(2)}$} & \multicolumn{2}{|c|}{ Enraizamento } & \multicolumn{2}{|c|}{ Número de raízes } \\
\hline & & 0 & $6.000 \mathrm{mg} \mathrm{L}^{-1}$ & 0 & $6.000 \mathrm{mg} \mathrm{L}^{-1}$ \\
\hline Sem folíolos & $8,0 \mathrm{c}$ & $0,0 \mathrm{aA}$ & $0,0 \mathrm{cA}$ & - & - \\
\hline Folíolos cortados ao meio & $32,7 b$ & $12,0 \mathrm{aA}$ & $23,3 \mathrm{bA}$ & $8,3 \mathrm{aA}$ & $8,4 \mathrm{bA}$ \\
\hline Folíolos inteiros & $65,5 \mathrm{a}$ & $16,0 \mathrm{aB}$ & $56,7 \mathrm{aA}$ & $2,3 \mathrm{bB}$ & $30,0 \mathrm{aA}$ \\
\hline
\end{tabular}

${ }^{(1)}$ Médias seguidas por letras iguais, maiúsculas nas linhas e minúsculas nas colunas, não diferem, pelo teste de Scott-Knott, a 5\% de probabilidade. ${ }^{\left({ }^{2}\right)}$ Sem interação entre os fatores. (-), ausência de enraizamento.

Tabela 4. Percentagem de sobrevivência e de enraizamento, e número de raízes nas estacas, em função de diferentes tipos de árvores matrizes de Toona ciliata var. australis e do uso de ácido indolbutírico (AIB) a 0 e $6.000 \mathrm{mg} \mathrm{L}^{-1(1)}$.

\begin{tabular}{|c|c|c|c|c|c|c|}
\hline \multirow[t]{2}{*}{ Árvores matrizes } & \multicolumn{2}{|c|}{ Sobrevivência } & \multicolumn{2}{|c|}{ Enraizamento } & \multicolumn{2}{|c|}{ Número de raízes } \\
\hline & 0 & $6.000 \mathrm{mg} \mathrm{L}^{-1}$ & 0 & $6.000 \mathrm{mg} \mathrm{L}^{-1}$ & 0 & $6.000 \mathrm{mg} \mathrm{L}^{-1}$ \\
\hline M02 & $30,4 \mathrm{bA}$ & $36,9 \mathrm{aA}$ & $15,0 \mathrm{bB}$ & $36,9 \mathrm{aA}$ & $8,4 \mathrm{aB}$ & $41,5 \mathrm{aA}$ \\
\hline M04 & $33,3 \mathrm{bA}$ & $11,1 \mathrm{bB}$ & $31,1 \mathrm{bA}$ & $11,1 \mathrm{bB}$ & $8,3 \mathrm{aB}$ & $37,2 \mathrm{aA}$ \\
\hline M05 & $40,0 \mathrm{bA}$ & $28,0 \mathrm{aA}$ & $40,0 \mathrm{aA}$ & $28,0 \mathrm{aA}$ & $19,4 \mathrm{aB}$ & $39,0 \mathrm{aA}$ \\
\hline M08 & $56,0 \mathrm{aA}$ & $16,0 \mathrm{bB}$ & $56,0 \mathrm{aA}$ & $16,0 \mathrm{bB}$ & $13,4 \mathrm{aB}$ & $31,9 \mathrm{bA}$ \\
\hline M10 & $30,0 \mathrm{bA}$ & $10,0 \mathrm{bA}$ & $30,0 \mathrm{bA}$ & $10,0 \mathrm{bB}$ & $12,6 \mathrm{aB}$ & $46,7 \mathrm{aA}$ \\
\hline M11 & $50,0 \mathrm{aA}$ & $50,0 \mathrm{aA}$ & $40,0 \mathrm{aA}$ & $40,0 \mathrm{aA}$ & $16,4 \mathrm{aA}$ & $24,6 \mathrm{bA}$ \\
\hline M16 & $51,8 \mathrm{aA}$ & $29,62 \mathrm{aA}$ & $48,1 \mathrm{aA}$ & $29,6 \mathrm{aA}$ & $11,8 \mathrm{aB}$ & $26,2 \mathrm{bA}$ \\
\hline
\end{tabular}

${ }^{(1)}$ Médias seguidas por letras iguais, maiúsculas nas linhas e minúsculas nas colunas, não diferem, pelo teste de Scott-Knott, a 5\% de probabilidade. 
relatada em clones de Eucalyptus spp. (Wendling \& Xavier, 2003).

Nas estacas coletadas das matrizes M04 e M08, quando se fez uso do AIB, observou-se maior mortalidade, que atingiu, respectivamente, 22,2 e $40,0 \%$ de diferença em relação às estacas sem AIB. O AIB pode provocar sintomas de fitotoxicidade, como amarelecimento ou queda das folhas, e podridão na base da estaca, o que causa muitas vezes a morte das estacas (Rocha et al., 2004). Este resultado é expresso em maior grau em determinadas árvores matrizes, como observado no presente estudo.

Praticamente todas as estacas sobreviventes enraizaram, o que, segundo Brondani et al. (2010), é indicação de adequado controle do ambiente em casa de vegetação e alta capacidade de enraizamento da espécie, mesmo que se trate de estacas coletadas de árvores adultas. Diferenças no enraizamento de estacas, em relação a plantas matrizes ou clones, foi destacada em estudo com Eucalyptus benthamii x Eucalyptus dunnii (Brondani et al., 2012) e Eucalyptus cloeziana (Almeida et al, 2007).

As sete árvores selecionadas para a avaliação da influência da planta matriz na sobrevivência e no enraizamento das estacas estavam sob condições edafoclimáticas e experimentais semelhantes, assim, as diferenças de enraizamento podem ser atribuídas às diferenças genéticas (material de origem seminal) e a fatores intrínsecos de cada árvore, que geram condições fisiológicas diferentes para cada matriz (Husen \& Pal, 2007; Li et al., 2009), pois flutuações da capacidade rizogênica podem ocorrer mesmo entre árvores estreitamente aparentadas, de acordo com o determinismo endógeno (Mankessi et al., 2009).

$\mathrm{O}$ processo de propagação vegetativa do cedro-australiano por estaquia deve ser ajustado à técnica de resgate de material vegetal, da área foliar nas estacas, e da árvore matriz em que será coletado o material, para que altos índices de enraizamento possam ser obtidos.

\section{Conclusões}

1. O corte raso produz maior número de brotos, e o semianelamento resulta em maior percentagem de enraizamento de estacas.

2. Estacas com dois pares de folíolos têm sobrevivência e enraizamento superiores.
3. O uso do ácido indolbutírico pode favorecer ou prejudicar o enraizamento, conforme a planta matriz utilizada; por isso, o manejo de reguladores de crescimento deve ser ajustado a cada material genético a ser multiplicado.

\section{Agradecimentos}

Ao Conselho Nacional de Desenvolvimento Científico e Tecnológico (CNPq), por concessão de bolsa; à Embrapa Floresta, pela concessão de logística e de estrutura para realização da pesquisa; e à empresa Berneck, pela permissão de uso da área de estudo.

\section{Referências}

ALMEIDA, F.D. de; XAVIER, A.; DIAS, J.M.M. Propagação vegetativa de árvores selecionadas de Eucalyptus cloeziana F. Muell. por estaquia. Revista Árvore, v.31, p.445-453, 2007. DOI: 10.1590/S0100-67622007000300010.

BITENCOURT, J.; ZUFFELLATO-RIBAS, K.C.; WENDLING, I.; KOEHLER, H.S. Enraizamento de estacas de erva-mate (Ilex paraguariensis A. St.-Hill.) provenientes de brotações rejuvenescidas. Revista Brasileira de Plantas Medicinais, v.11, p.277-281, 2009.

BRONDANI, G.E.; BACCARIN, F.J.B.; WIT ONDAS, H.W. de; GONÇALVES, A.N.; ALMEIDA, M. de. Avaliação morfológica e produção de minijardim clonal de Eucalyptus benthamii em relação a Zn e B. Pesquisa Florestal Brasileira, v.32, p.151-164, 2012. DOI: 10.4336/2012.pfb.32.70.35.

BRONDANI, G.E.; WENDLING, I.; GROSSI, F.; DUTRA, L.F.; ARAUJO, M.A. Miniestaquia de Eucalyptus benthamii $\mathrm{x}$ Eucalyptus dunnii: (II) sobrevivência e enraizamento de miniestacas em função das coletas e estações do ano. Ciência Florestal, v.20, p.453-465, 2010 .

BYGRAVE, F.L.; BYGRAVE, P.L. Growing Australian red cedar and other Meliaceae species in plantation. Canberra: Rural Industries Research and Development Corporation, 2005. 84p. (Publication, 04/135).

COSTA, C.T. da; ALMEIDA, M.R. de; RUEDELL, C.M.; SCHWAMBACH, J.; MARASCHIN, F.S.; FETT-NETO, A.G. When stress and development go hand in hand: main hormonal controls of adventitious rooting in cuttings. Frontiers in Plant Science, v.4, article 133, 2013. DOI: 10.3389/fpls.2013.00133.

DIAS, P.C.; XAVIER, A.; OLIVEIRA, L.S.; PAIVA, H.N.; CORREIA, A.C.G. Propagação vegetativa de progênies de meios-irmãos de angico-vermelho (Anadenanthera macrocarpa (Benth) Brenan) por miniestaquia. Revista Árvore, v.36, p.389-399, 2012. DOI: 10.1590/S0100-67622012000300001.

FERREIRA, D. de A.; BARROSO, D.G.; SILVA, M.P.S. da; SOUZA, J.S. de; FREITAS, T.A.S. de; CARNEIRO, J.G. de A. Influência da posição das miniestacas na qualidade de mudas de cedro australiano e no seu desempenho inicial no 
pós-plantio. Ciência Florestal, v.22, p.715-723, 2012. DOI: 10.5902/198050987553.

FOCHESATO, M.L.; MARTINS, F.T.; SOUZA, P.V.D.; SCHWARZ, S.F.; BARROS, I.B.I. Propagação de louro (Laurus nobilis L.) por estacas semilenhosas com diferentes quantidades de folhas e tratadas com ácido indolbutírico. Revista Brasileira de Plantas Medicinais, v.8, p.72-77, 2006.

HARTMANN, H.T.; KESTER, D.E.; DAVIES JR, F.T.; GENEVE, R.L. Hartmann and Kester's plant propagation: principles and practices. $8^{\text {th }}$ ed. Boston: Prentice Hall, 2011. 928p.

HUSEN, A.; PAL, M. Metabolic changes during adventitious root primordium development in Tectona grandis Linn. f. (teak) cuttings as affected by age of donor plants and auxin (IBA and NAA) treatment. New Forests, v.33, p.309-323, 2007. DOI: 10.1007/s11056-006-9030-7.

LAMÔNICA, K.R. Produtividade de minicepas de clones de cedro australiano (Toona ciliata) e produção de mudas por miniestaquia. 2013. 76p. Tese (Doutorado)-Universidade Estadual do Norte Fluminense, Campos dos Goytacazes.

LI, S.-W.; XUE, L.G.; XU, S.J.; FENG, H.Y.; AN, L.Z. Mediators, genes and signaling in adventitious rooting. Botanical Review, v.75, p.230-247, 2009. DOI: 10.1007/s12229-009-9029-9.

LUO, J.P.; ZHAND, J.C.; WANG, Y. Changes in endogenous hormone levels and redox status during enhanced adventitious rooting by rare earth element neodymium of Dendrobium densiflorum shoot cuttings. Journal of Rare Earths, v.26, p.869-874, 2008. DOI: 10.1016/S1002-0721(09)60023-5.

MANKESSI, F.; SAYA, A.; BAPTISTE, C.; NOURISSIER, S.; MONTEUUIS, O. In vitro rooting of genetically related Eucalyptus urophylla $\mathrm{x}$ Eucalyptus grandis clones in relation to the time spent in culture. Trees, v.23, p.931-940, 2009. DOI: 10.1007/ s00468-009-0335-y.

RAST, E.D.; BEATON, J.A.; SONDERMAN, D.L. Photographic guide to selected external defect indicators and associated internal defects in black walnut. Broomall: United States Department of Agriculture, 1988. 24p. (Research paper, NE-617).

ROCHA, S.C. da; QUISEN, R.C.; QUEIROZ, J.A.L. de; ZUFFELLATO-RIBAS, K.C. Propagação vegetativa de espirradeira pela técnica da estaquia. Scientia Agraria, v.5, p.73-77, 2004. DOI: 10.5380/rsa.v5i1.1100.

SANTIN, D.; WENDLING, I.; BENEDETTI, E.L.; BRONDANI, G.E.; REISSMANN, C.B.; MORANDI, D.; ROVEDA, L.F. Poda e anelamento em erva-mate (Ilex paraguariensis) visando à indução de brotações basais. Pesquisa Florestal Brasileira, n.56, p.97-104, 2008.

SANTOS, A.M. Melhoramento genético do cedro australiano (Toona ciliata M. Roemer var. australis). 2011. 64p. Tese (Doutorado) - Universidade Federal de Lavras, Lavras.

SANTOS, H.G. dos; JACOMINE, P.K.T.; ANJOS, L.H.C. dos; OLIVEIRA, V.A. de; OLIVEIRA, J.B. de; COELHO, M.R.;
LUMBRERAS, J.F.; CUNHA, T.J.F. (Ed.). Sistema brasileiro de classificação de solos. 2.ed. Rio de Janeiro: Embrapa Solos, 2006. $306 \mathrm{p}$.

SILVA, M.P.S. da; BARROSO, D.G.; SOUZA, J.S. de; FERREIRA, D. de A.; CARNEIRO, J.G. de A. Enraizamento de miniestacas e produtividade de minicepas de cedro-australiano manejadas em canaletões e tubetes. Ciência Florestal, v.22, p.703-713, 2012. DOI: $10.5902 / 198050987552$.

SINGH, S.; ANSARI, S.A. Mass multiplication of mature trees of Gmelina arborea Roxb. through ex vitro rooting of rejuvenated bud sprouts. Research Journal of Forestry, v.8, p.25-31, 2014. DOI: $10.3923 /$ rjf.2014.25.31.

SOUZA, C.C.; XAVIER A.; LEITE, F.P.; SANTANA, R.C.; LEITE, H.G. Padrões de miniestacas e sazonalidade na produção de mudas clonais de Eucalyptus grandis Hill X E. urophylla S. T. Black. Revista Árvore, v.37, p.67-77, 2013. DOI: 10.1590/ S0100-67622013000100008.

SOUZA, J.C.A.V. de; BARROSO, D.G.; CARNEIRO, J.G. de A.; TEIXEIRA, S.L.; BALBINOT, E. Propagação vegetativa de cedro australiano (Toona ciliata M. Roemer) por miniestaquia. Revista Árvore, v.33, p.205-213, 2009. DOI: 10.1590/ S0100-67622009000200002.

STENVALL, N.; PIISILÄ, M.; PULKKINEN, P. Seasonal fluctuation of root carbohydrates in hybrid aspen clones and its relationship to the sprouting efficiency of root cuttings. Canadian Journal of Forest Research, v.39, p.1531-1537, 2009. DOI: 10.1139/X09-066.

WENDLING, I.; BRONDANI, G.E.; BIASSIO, A. de; DUTRA, L.F. Vegetative propagation of adult Ilex paraguariensis trees through epicormic shoots. Acta Scientiarum. Agronomy, v.35, p.117-125, 2013. DOI: 10.4025/actasciagron.v35i1.15958.

WENDLING, I.; DUTRA, L.F.; HOFFMANN, H.A.; BETTIO, G.; HANSEL, F. Indução de brotações epicórmicas ortotrópicas para a propagação vegetativa de árvores adultas de Araucaria angustifolia. Agronomía Costarricense, v.33, p.309-319, 2009.

WENDLING, I.; TRUEMAN, S.J.; XAVIER, A. Maturation and related aspects in clonal forestry-part II: reinvigoration, rejuvenation and juvenility maintenance. New Forests, v.45, p.473-486, 2014. DOI: 10.1007/s11056-014-9415-y.

WENDLING, I.; XAVIER, A. Miniestaquia seriada no rejuvenescimento de clones de Eucalyptus. Pesquisa Agropecuária Brasileira, v.38, p.475-480, 2003. DOI: 10.1590/ S0100-204X2003000400005.

XAVIER, A.; SANTOS, G.A. dos; OLIVEIRA, M.L. de. Enraizamento de miniestaca caulinar e foliar na propagação vegetativa de cedro-rosa (Cedrela fissilis Vell.). Revista Árvore, v.27, p.351-356, 2003. DOI: 10.1590/ S0100-67622003000300011.

XAVIER, A.; WENDLING, I.; SILVA, R.L. da. Silvicultura clonal: princípios e técnicas. 2.ed. Viçosa: Ed. UFV, 2013. 272p.

Recebido em 19 de outubro de 2014 e aprovado em 4 de março de 2015 